\title{
Predicting salt damage in practice: a theoretical insight into laboratory tests
}

\author{
Robert J. Flatt ${ }^{\mathrm{a}}$, Nevin Aly Mohamed ${ }^{\mathrm{a}, \mathrm{b}}$, Francesco Caruso $^{c}$, Hannelore Derluyn $^{\mathrm{d}}$, Julie Desarnaud ${ }^{e}$, \\ Barbara Lubelli ${ }^{f}$, Rosa Maria Espinosa-Marzal ${ }^{\mathrm{g}}$, Leo Pel ${ }^{\mathrm{h}}$, Carlos Rodriguez-Navarro', George W. Scherer, \\ Noushine Shahidzadeh" ${ }^{k}$ Michael Steiger'
}

\author{
aTH Zurich, Switzerland \\ ${ }^{\mathrm{b}}$ Suez University, Egypt \\ 'University of Oslo, Norway \\ ${ }^{\mathrm{d}}$ CNRS - Univ Pau \& Pays Adour, France \\ e The Getty Institute, USA \\ ${ }^{f}$ TU Delft, The Netherlands \\ ${ }^{g}$ University of Illinois at Urbana Champaign, USA \\ ${ }^{\mathrm{h}}$ Eindhoven University of Technology, The Netherlands \\ Universtiy of Granada, Spain \\ jPrinceton University, USA \\ k University of Amsterdam, The Netherlands \\ University of Hamburg, Germany
}

Received: 30 November 2017 / Accepted: 28 December 2017 / Published online: 31 December 2017

C The Author(s) 2017. This article is published with open access and licensed under a Creative Commons Attribution 4.0 International License.

\begin{abstract}
Salt crystallization represents one of the major causes for the degradation of building and ornamental stone. As such, it has attracted the attention of researchers, who over the years have progressively unraveled most mechanisms involved in salt damage. Despite this mechanistic understanding, many questions subsist about how to quantitatively predict damage or its progression, and in particular how to relate performance on site to that in laboratory tests.

In this context, a new RILEM TC 271-ASC has been started with the objective of defining laboratory tests that deliver more reliable predictions of field behavior. One deliverable of this TC is to provide a theoretical insight into this question based on recent progress on the understanding of salt damage. This paper presents a summary of this work, highlighting key aspects relating to crystallization pressure, chemo-mechanics and mass transport. Implications are discussed in relation to the most used accelerated salt crystallization tests in an attempt to better define which field exposure conditions that these tests best represent and may be used for, or define effective test procedures representing specific field conditions.

A simple conceptual model for the development of salt damage is introduced. During an initial "induction" phase, transport of ions and accumulation of salt in the porous materials occurs without causing detectable damage until a critical point, termed "damage onset" is reached. Beyond this point, during the "propagation phase", the material degrades, typically losing strength and cohesiveness. The implications of these two phases are discussed in relation to the selection of appropriate salt weathering tests and conservation interventions.
\end{abstract}

Keywords: Cultural heritage; Stone; Brick; Masonry; Salt Damage; Crystallization pressure; Salt testing; Sodium sulfate; Sodium chloride; Conservation

\section{Introduction}

Stones and masonry materials exposed to the environment are subject to physical, chemical and biological weathering that can damage these materials over time. Different deterioration patterns are known and, in the case of stone, well described in the ICOMOS-ISCS glossary [1]. In many situations, this degradation is due to the action of various types of soluble salts entrapped in masonry from internal or external sources or a combination of both. Internal sources involve the dissolution or chemical transformation of the material itself or the use of salt-rich materials (e.g. dolomitic and cement-based mortars) [2]. External sources can be the vicinity of the sea, animal excrements, agriculture, deicing salts, microorganisms, conservation treatments (e.g. $\mathrm{Na}$ - and $\mathrm{K}$ - silicates waterglass), or capillary rise of ground water [3]. Acid attack of limestone or lime-based mortars from atmospheric pollution, in particular sulfur dioxide, leads to

* Corresponding author: Robert J. Flatt, E-mail: flattr@ethz.ch 
the formation of gypsum and represents a typical case of a combination of internal and external sources.

Prediction of salt damage is particularly challenging. The most widely used standard test, EN 12370 [4], relies on cycles of impregnation by full immersion of specimens in a sodium sulfate solution, followed by drying at $105^{\circ} \mathrm{C}$. This leads to damage during the re-wetting phase of a cycle and, because of the contamination procedure and the extreme salt load and drying temperature, is not expected to be representative for most situations found in practice, as for example capillary rise. Several attempts to mimic field situations in laboratory salt weathering tests have been performed [5-9]. However, their relevance is questionable since their outcome depends on the test conditions, with for example substantial changes in ranking of stone resistance depending on whether the test involve complete or partial immersion [10]. Therefore, the issue of knowing how to obtain reliable results from accelerated testing remains open. This paper represents an effort of members of RILEM TC 271-ASC to compile theoretical insights regarding factors that influence the resistance of masonry to salt damage in relation to exposure conditions, and which should be incorporated into standard tests.

The paper begins with an overview of crystallization pressure, which is the mechanism through which damage develops (section 2). A particularly important feature is upscaling pressure from the pore scale to the material scale. Poromechanics shows that macroscopic damage onset depends on crystallization pressure, the amount of salt accumulated and materials properties. Thus, the accumulation rates and localization of supersaturation, which depend on exposure conditions, play important roles as drivers for crystallization pressure. An overview of these factors is given in section 3 , followed by a discussion of factors that control rates of salt transport in porous materials (section 4).

Analyzing salt damage thus involves transport kinetics, environmental exposure, materials chemistry, and poromechanics. In view of this complexity, numerical modelling of these coupled processes is essential to quantify "exposure conditions" and design relevant tests. To this end, section 5, presents an overview of the state of the art of numerical modelling for salt transport and associated damage from crystallization pressure. Owing to space restrictions, we do not cover the more recently discussed topic of diffusiophoresis, whereby some salts establish a concentration gradient capable to transport colloidal particles towards tiny pores that are not accessible by flow otherwise [11].

The paper concludes with a simple conceptual model for the development of salt damage. During an initial "induction" phase, transport of ions and accumulation of salt in the porous materials occur without causing detectable damage until a critical point, termed "damage onset" is reached. Beyond this point, during the "propagation phase", the material degrades increasingly. The implications of these two phases are discussed in relation to the selection of appropriate salt weathering tests and conservation interventions.

\section{Chemo-mechanics of crystallization pressure}

\subsection{Concept of crystallization pressure and supersaturation}

The crystals in Fig. 1 are surrounded by a solution containing the same ions that constitute the crystal. Each is separated from the pore wall by a nanometric film (thickness $\delta$ ) owing to a repulsive "disjoining" pressure, $P_{d}$, that exists because the salt/mineral interface that would result from contact with the wall has a higher energy than the sum of the existing salt/solution and mineral/solution interfaces [1214]. If the solution is supersaturated, then the pressure, $P_{C}$, required to suppress growth of the crystal is $[13,15]$ (see Supplementary Material):

$\left(P_{C}-P_{0}\right)=\frac{R T}{v_{C}} \ln \left(\frac{Q}{K}\right)$

where $P_{0}$ is the pressure on the liquid, $R$ the gas constant, $T$ the absolute temperature, $v_{C}$ the molar volume of the crystal, $Q$ the ion activity product (see suppl. mat.), and $K$ the equilibrium activity product at $P_{0}$ (equal to $Q$ at saturation). The ratio $Q / K$ is called "supersaturation" and is a measure of the thermodynamic driving force for a chemical transformation of which the energy may produce damaging mechanical work.

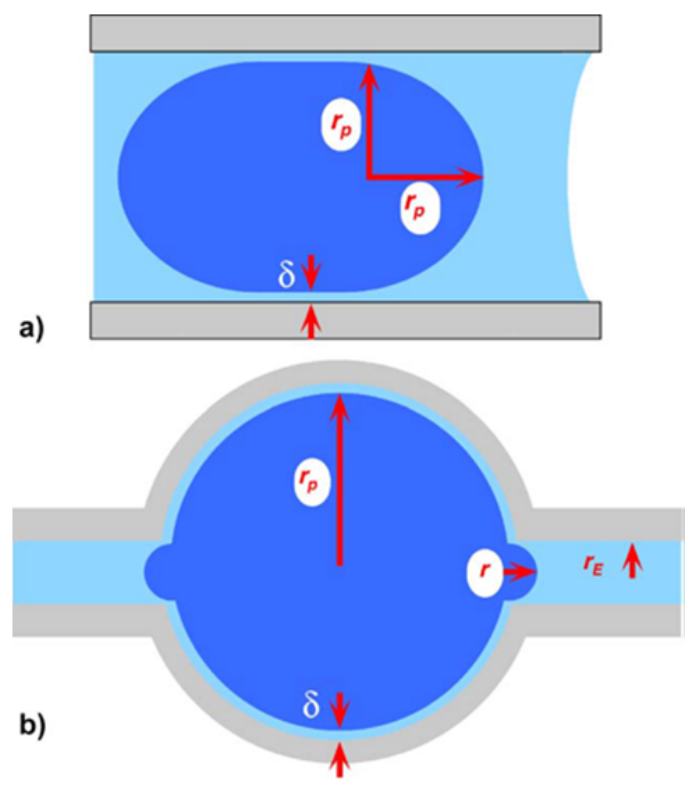

Figure 1. If the crystal grows in a cylindrical pore with radius $r_{p}$, then the end of the crystal is hemispherical and has curvature $\kappa_{C L}^{E}=$ $2 /\left(r_{p}-\delta\right)$, whereas the cylindrical side has curvature $\kappa_{C L}^{S}=$ $1 /\left(r_{p}-\delta\right)$. Here, $\delta$ is the thickness of the liquid film between the crystal and the pore wall. (b) When a crystal grows in a large pore $\left(r_{p}\right.$ macroscopic) with small entries (radius $r_{E} \ll r_{p}$ ), the curvature of the body of the crystal is $\kappa_{C L}^{S} \approx 0$, and the crystallization pressure is determined by the curvature of the crystal in the pore entries, $\kappa_{C L}^{E}=$ $2 /\left(r_{E}-\delta\right)$. Reproduced with authorization from [13]. 
The maximum crystallization pressure is bounded by the disjoining pressure: if the supersaturation is so high that $P_{C}>$ $P_{d}$, then the crystal will touch the wall and growth will stop. This implies that modifying interfacial energies in porous materials may offer a means of mitigating salt damage [16]. Such issues are, however, not considered in this paper, which uses Equation (1) as the basis for the discussion.

\subsection{Measurement of crystallization pressure}

Correns and Steinborn proposed the first equation for crystallization pressure $[17,18]$, but they erroneously expressed supersaturation as a concentration ratio [19]; nevertheless, their experimental data matched very well with their incorrect equation. This and experimental shortcomings raised $[19,20]$ - as well as the failure of other researchers to directly measure crystallization pressure $[21,22]$ - led to questioning the concept altogether. More recently, Desarnaud et al. [23] used a novel experimental approach to directly quantify the crystallization pressure. Other earlier experiments also contributed to establishing the existence of crystallization pressure [24-26].

\subsection{Conditions allowing crystallization pressure to develop}

\subsubsection{Small pores}

In small pores, crystals require a certain supersaturation to subsist because of curvature effects $[12,27]$ that increase $K$ for small crystals [28], so $P_{\mathrm{C}}$ is smaller at a given $Q$. As an example, in cylindrical pores, the crystallization pressure may drop to as little as half of that defined in Eq. (1). This situation is illustrated in Fig. 1a, which shows a crystal in equilibrium in a cylindrical pore of radius $r_{p}$. The crystal end is hemispherical with a curvature $\kappa_{C L}^{E}=2 /\left(r_{p}-\delta\right)$, where $\delta$ is the liquid film thickness. The curvature on the crystal side is $\kappa_{C L}^{S}=1 /\left(r_{p}-\delta\right)$. This crystal can subsist if the supersaturation allows for a curvature $\kappa_{C L}^{E}$, in which case the sides are supersaturated, trying to grow and pushing against the wall with pressure $\gamma_{C L} /\left(r_{p}-\delta\right)=P_{C} / 2$. This equilibrium situation can develop pressure without the pore having to be filled and without having to introduce kinetic arguments.

\subsubsection{Filled large pores}

The pore size in natural stones, fired-clay bricks and limebased mortars is much larger than in concrete (tens of microns instead of nanometers). This means that the situation described above is rather unlikely to cause large crystallization pressures in these materials. Another possibility is described in Fig. $1 \mathrm{~b}$. It represents a large pore filled with a crystal having over most of its surface a curvature $\kappa_{C L}^{S}=2 /\left(r_{p}-\delta\right)$. This pore is connected to smaller pores with an entry radius $r_{E} \ll r_{p}$. The maximum supersaturation before the crystal propagates through those pores is given by the curvature $\kappa_{C L}^{E}=2 /\left(r_{E}-\delta\right)$. Under such conditions, the full pressure described in Eq. (1) is applied to the walls of the large pore. However, this situation is also expected to be rather rare in most natural stones because large pores are not generally isolated by small entries, as assumed in Fig.1b.
In natural environments, salts deposit rather slowly, so stressed crystals dissolve and the ions diffuse to larger pores (a process called Ostwald ripening), where crystals can grow without restraint. Salt damage should therefore only begin after salt loadings are high enough to fill a substantial fraction of the pores. Crystallization pressure can result from salt filling large pores if, as shown in Fig. 2, drying causes the liquid film to retreat between the salt crystal and the pore wall: the supersaturated film generates pressure limited only by $P_{\mathrm{d}}$. Salt-filled pores can also cause damaging pressure during insolation, owing to thermal expansion mismatch between salt and porous materials [16].

Clearly, salt loading and distribution are important factors that should be mimicked by laboratory tests. However, any attempt to reduce the exposure time while "loading" the material with salt probably modifies their distribution in the material (section 4).

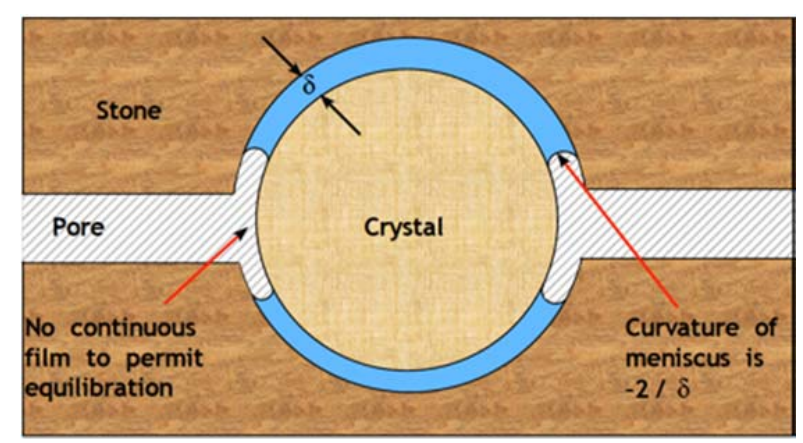

Figure 2. Situation in which drying has proceeded to the point that the meniscus lies between the crystal and the pore wall, so that ions cannot diffuse to the hemispherical end of the crystal. Consequently, the supersaturation in the liquid cannot be relieved by further growth (adapted from [13]).

\subsubsection{Sustained high supersaturation}

One mechanism producing a high supersaturation involves the dissolution-mediated transformation from a highly soluble phase to one of lower solubility [29]. Sodium sulfate, which is one of the most damaging salts known, constitutes a good example of this. Thenardite (sodium sulfate anhydrous) precipitates during drying cycles and dissolves during subsequent wetting. Below $32.4{ }^{\circ} \mathrm{C}$, this produces a solution supersaturated with respect to mirabilite (sodium sulfate decahydrate) [30-32], the precipitation of which can cause substantial damage. In concrete, delayed ettringite formation also proceeds via a temperature-related phase transformation [33,34]. A more complete treatment of sodium sulfate phase transitions with corresponding crystallization pressure calculations as a function of temperature and of the anhydrous sodium sulfate phase (III or V) is given elsewhere [35]. Other hydrated salts, such as magnesium sulfate, can behave analogously [36-41].

Phase transformations can produce high supersaturations throughout large portions of porous materials and are, therefore, very destructive. This explains the popular use of sodium sulfate in accelerated salt tests involving cycles of wetting and drying [4]. 


\subsection{Mechanics and micro-mechanics of salt damage}

Predicting damage from salt crystallization has haunted researchers for decades. Thomson [42] explained that a tensile stress is produced in the matrix of a porous material when crystals grow in the pores. The tensile strength of the material should therefore be considered and salts must propagate through a large enough fraction of the porous network to produce stress fields capable of propagating strength-limiting flaws [12] (the largest defect in a material that are known to control its tensile strength).

Coussy quantified the macroscopic tensile stress felt by the material due to crystallization by coupling crystallization pressure with poromechanics [43] for isothermal situations, which greatly simplifies the analytical solution. This macroscopic tensile stress is:

$\sigma^{*}=\sigma_{r} b S_{C}$

where $\sigma_{r}$ is the radial compressive stress, i.e. the applied crystallization pressure on the pore wall, and hence, it is roughly given by (1) for filled pores, $b$ is the Biot coefficient (for limestones roughly equal to 1-exp(-6.4 $\varphi$ ) where $\varphi=$ porosity [44]) and $S_{C}$ is the volume fraction of the porous network filled with crystals. Using a strain energy failure criterion, damage is expected to begin if a critical stress, $\sigma_{C}^{*}$, is reached [25]:

$\sigma_{C}^{*}=\sigma_{T} / \sqrt{3(1-2 v)}$

where $\sigma_{T}$ is the tensile strength of the material and $v$ its Poisson ratio (for stone, $v$ typically ranges from 0.2 to 0.35 ).

The predictive power of this relation was demonstrated using the sodium sulfate test at different temperatures [26]. The supersaturation and, therefore, $\sigma_{r}$ were varied by changing the wetting temperature because of the strong temperature dependence of the solubility of mirabilite. Experiments showed that lower temperatures required fewer impregnation cycles for damage to occur, because the crystallization pressures were higher. More importantly, the number of cycles needed to cause damage can be determined from Eqs. (2) and (3) with $\sigma_{r}$ given by Eq. (1) [26].

Thus, if supersaturation and salt loading are known, then damage onset just depends on knowing the tensile strength and Poisson ratio. An example of such a situation is the cyclic impregnation and drying with sodium sulfate solutions [26], or the evaporative crystallization of sodium sulfate in a porous material [29]. However, in most practical situations the supersaturation is not known. Therefore, a major challenge for testing materials for salt damage consists in reproducing a combination of salt loading and supersaturation representative of weathering events in situ.

\section{Conditions of exposure}

\subsection{Capillary Rise}

A common mechanism by which salts can be supplied to and accumulated within a built structure is rising damp [2,5] (Fig. 3a). Ground water is a diluted salt solution that can rise up a wall by capillary forces (so-called "wick effect") [6]. Once the salt solution reaches the exposed surface of the wall, it evaporates [45] and each salt starts to crystallize at a certain height once a sufficient supersaturation is reached. Less soluble salts crystallize at lower heights, while more soluble salts crystallize higher up following a "chromatographic" separation (fractionation) [2]. If evaporation takes place at the wall surface, non-damaging efflorescence forms (crystals forming on the surface of the porous material and that can be considered as visual damage) [46]. At a certain height, in contrast, the evaporation front retreats into the pore network and damaging subflorescence forms (crystals forming within the porous material). The dynamic equilibrium between evaporative flux (drying) and advective supply of solution to the evaporation front dictates the transition height from efflorescence to subflorescence (Fig. 3a and b) [7,13,45,47].

Existing standard tests or recommendations, for example RILEM 25-PEM (1980) and EN12370 [4,48], do not directly assess this transition. Test procedures involving partial immersion can better reproduce it. A continous partial immersion test was proposed by Rodriguez-Navarro and Doehne $[5,8]$. Fig. $3 b$ and $3 c$ show results where a prism of the stone is partially immersed in a saline solution covered with paraffin (to avoid excessive evaporation and promote capillary flow through the pore system of the sample). Typically, efflorescence forms up to a certain height, above which subflorescence causes damage in the form of cracks, scaling and granular disintegration (Fig. 3d).

Once a sufficient amount of salt has accumulated within the pores, high stresses and damage can arise [26]. The partial immersion test shown in Fig. $3 \mathrm{~b}$ has been used not only to evaluate the susceptibility of different porous materials against salt damage, or to rank the damage potential of different salts $[5,7,13,40,49]$, but also to evaluate the efficacy of crystallization inhibitors-promoters to reduce salt damage [50-55] and to favor desalination by fostering efflorescence (Fig. 3e) [56,57]. A modification of this test was proposed by Hamde et al., applying a continuous flow of $10 \%$ sodium chloride [58]. With this they could clearly illustrate how increasing temperature to accelerate drying, shifted crystallization from efflorescence without damage to damaging subflorescence. One limitation of these partial immersion tests, as well as of other procedures, is the current lack of a specific normative that could enable direct comparison of test results among different laboratories. 


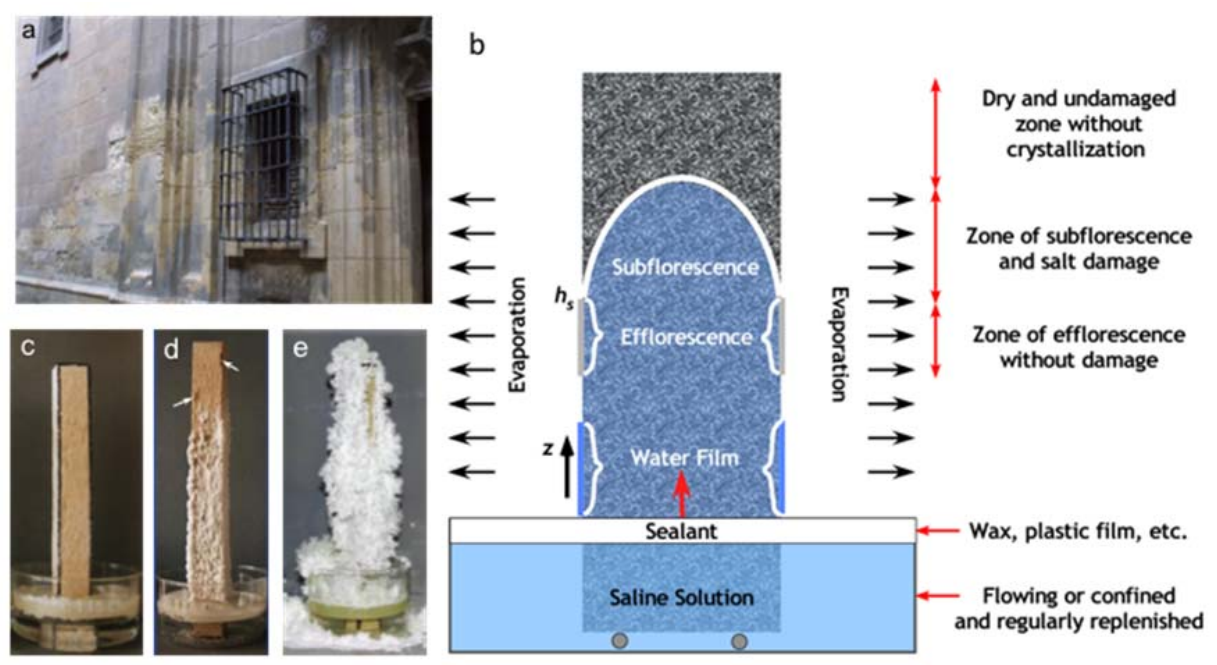

Figure 3. Salt damage via capillary rise. a) Example of a porous calcarenite stone wall (Granada Cathedral, Spain) affected up to a certain height (marking the maximum height of capillary rise) by salt damage; b) scheme showing the partial immersion test for salt damage via capillary rise, representing: capillary rise, evaporation and zones of efflorescence and subflorescence (adapted from [13]); different sealants have been proosed as paraffin wax [5] and flexible plastic films [13], the solution max be still and replenished [13] or in continuous flow [58], most preferably such samples are placed in a chamber of which the environmental conditions are controlled [5,7], and the sample is placed on supports so that the solution wets the bottom surface [7]; c) image of the partial immersion test set up for the case of a porous limestone subjected to sodium chloride crystallization test; d) same as (c) after four weeks solution flow-through and evaporation. Efflorescence in the lower part of the stone prism is observed, while subflorescence in the upper part leads to scaling and loss of material (arrows); and e) porous limestone subjected to sodium chloride crystallization in the presence of $3 \mathrm{mmol} / \mathrm{L}$ sodium ferrocyanide. Just in two days, massive salt extraction as efflorescence takes place in the presence of this crystallization inhibitor (image reproduced with permision from [51]).

\subsection{Temperature, relative humidity and wetting cycles}

Another important mechanism by which weathering takes place is dissolution-recrystallization cycles of salt crystals entrapped in porous materials (see section 2.3.3). With wetting, temperature and/or relative humidity (RH) fluctuation, the salts can dissolve either in contact with liquid water (dissolution) or with water vapor in the air (deliquescence). The latter occurs when the RH of the air exceeds the equilibrium $\mathrm{RH}$ of the saturated salt solution. In porous materials, the resulting salt solution is subsequently mobilized in the pore network and can re-crystallize in another location when environmental conditions change.

Laboratory studies $[25,31,37,59-63]$ have shown how the kinetic pathway of recrystallization can influence the way different salts cause damage depending on environmental conditions. Serious damage, such as granular disintegration (Fig. 4a) and substantial redistribution of salt (Fig. 4b and 4c) can result from $\mathrm{RH}$ cycles alone. Wetting with liquid water (e.g., rain or capillary rise/rising damp) may result in damage, as shown in Fig. 3, or harmless efflorescence, as in Fig. 5. Such results can be explained by models that take account of the duration and rate of the wetting and drying cycles, respectively, as explained in section 4 .
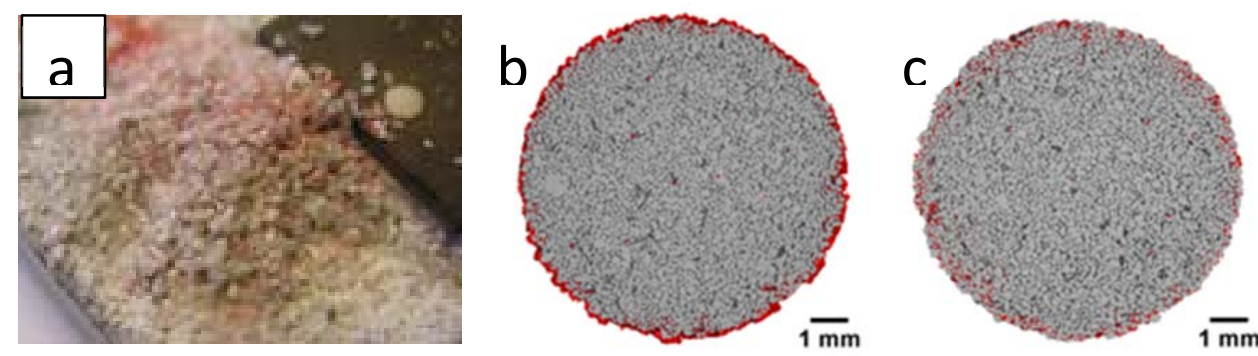

Figure 4. Illustration of the formation of granular disintegration (a) from [59] and of the displacement of sodium chloride as a result of cycles of humidifying at $92 \% \mathrm{RH}$ and drying at $10 \% \mathrm{RH}$ [62]. b) shows a micro $\mathrm{CT}$ image of a sample impregnated with a $\mathrm{NaCl}$ solution and dried once, while c) shows the same sample after 3 cycles. The red color shows the $\mathrm{NaCl}$ and its displacement from outside the sample to its subsurface. Reproduced with authorization from [59] and [62]. 

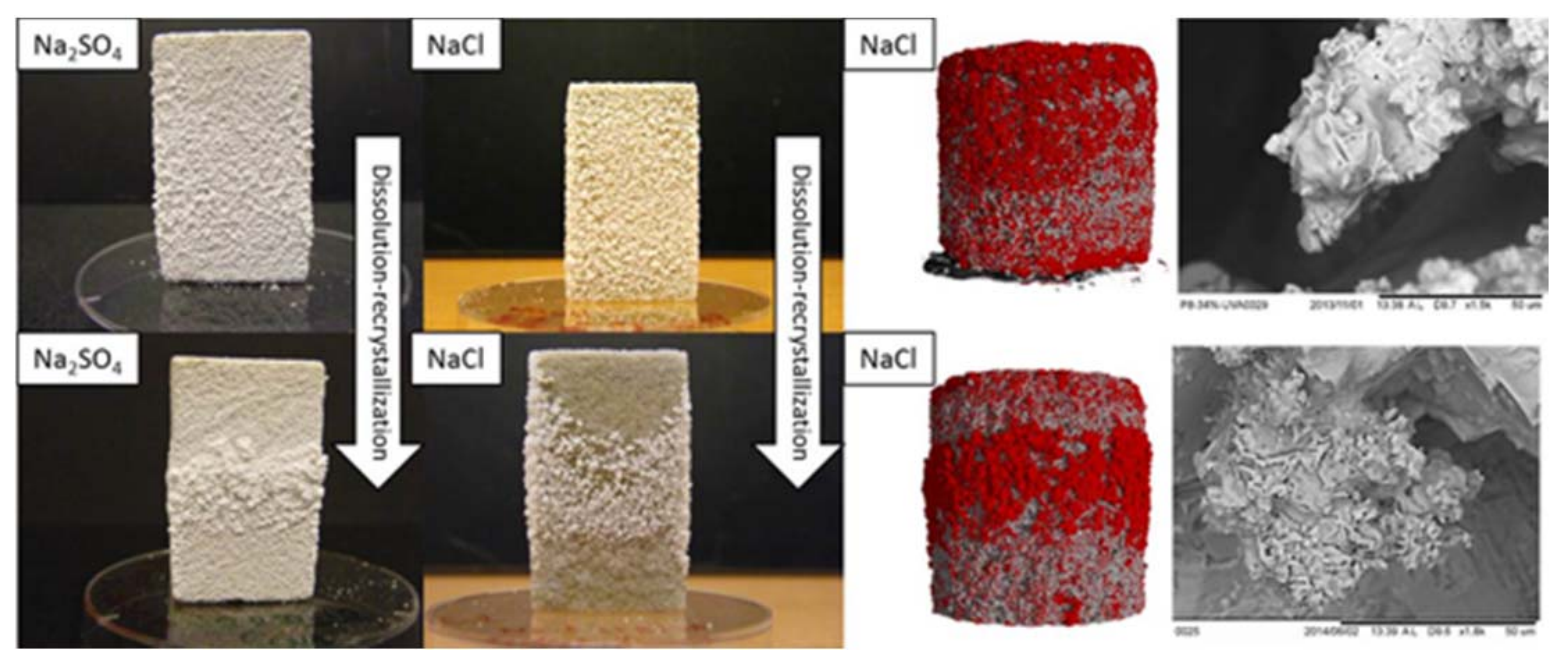

Figure 5. Salts contaminated stones (top images) are saturated with water and dried again (bottom images). Recrystallization in this way tends to extract the salt from the porous stone and favors more localised cauliflowers structures as efflorescence. X-ray $\mu$-CT analysis of $\mathrm{NaCl}$ at the surface after dissolution recrystallization. The SEM images show the larger size of $\mathrm{NaCl}$ cauliflowers efflorescence after several cycles [94]. Reproduced with authorization from [94].

For salts that have both hydrated and anhydrous phases with different temperature-dependent solubilities, the crystallization dynamics can be more complex. As mentioned in section 2.3.3, for most of these salts, such as magnesium sulfate or sodium sulfate, it is rather the direct dissolution/recrystallization cycles that induce significant damage $[25,30,31,37,60,63]$.

\subsection{Salt mixtures}

Though most laboratory experiments are carried out with single salts, contamination of porous building materials with only one salt is quite uncommon. Usually, complex mixtures of salts are present. The crystallization of salt mixtures is much more complex $[64,65]$ and few studies with salt mixtures exist (e.g. [66-70]). At a given temperature, the behavior of a single salt is well described by its solubility and deliquescence humidity (DRH). Above the DRH, the salt remains dissolved, while below it the salt crystallizes out. Therefore, experimental conditions in the above described experiments are well defined for single salts.

In salt mixtures, the solubility of a salt is affected by the other salts and strongly depends on the mixture composition. In effect, crystallization properties of salt mixtures are not characterized by a single DRH value but rather a range. The more complex a mixture is, the broader is the $\mathrm{RH}$ range across which solution and solid phases coexist. This results in fractionation of salt mixtures during transport due to selective precipitation as described in section 3. The prediction of the crystallization behavior of complex salt mixtures requires thermodynamic modeling [65].

Another complicating factor arises from the fact that a large number of double salts may form in mixed solutions [65]. A congruently soluble double salt, e.g. $\mathrm{KAl}\left(\mathrm{SO}_{4}\right)_{2} \cdot 12 \mathrm{H}_{2} \mathrm{O}$ (potassium alum), behaves like a single salt and may be characterized by an unambiguous DRH and solubility. However, most double salts found in building materials are incongruently soluble $[36,70,71]$. Dissolution of such a compound yields a metastable solution that is supersaturated with one of the two single salt constituents. For example, dissolution of both darapskite, $\mathrm{Na}_{3} \mathrm{NO}_{3} \mathrm{SO}_{4} \cdot \mathrm{H}_{2} \mathrm{O}$, and bloedite, $\mathrm{Na}_{2} \mathrm{Mg}\left(\mathrm{SO}_{4}\right)_{2} \cdot 4 \mathrm{H}_{2} \mathrm{O}$, leads to a mixed solution highly supersaturated with respect to mirabilite, $\mathrm{Na}_{2} \mathrm{SO}_{4} \cdot 10 \mathrm{H}_{2} \mathrm{O}$. Thus, upon wetting, these double salts behave similarly to pure sodium sulfate and were found to be very damaging in wetting experiments at high pore filling $[36,71]$.

\section{Transport mechanisms}

Mass transport rates, which play a dominant role in the induction period before salt damage, are analyzed in this section, based largely on [72-75].

\section{1 lon transport: advection and diffusion}

As long as there is no moisture transport, ions only diffuse within the liquid. In a porous material, their diffusion is hindered by the tortuosity, $T^{*}$, of the pore structure, which increases the effective path length. Neglecting adsorption on the pore wall, the diffusion in a porous body writes:

$\frac{\partial c}{\partial t}=\frac{\partial}{\partial x}\left(D_{e f f} \frac{\partial c}{\partial x}\right)$

where $c$ is the ion concentration, $D_{\text {eff }}$ the effective diffusivity for a given material. For a porous material this writes $D_{\text {eff }}=D / T^{*}$, where $D$ is the diffusion coefficient in water. In general, for many porous materials $T^{*}$ is in the order of 410.

When there is also a moisture flow (or advection), which represents most cases of practical interest, ions are 
transported along with the liquid. Simultaneously to this advection, ions continue to move in response to the concentration gradient, something that for a fully saturated sample is described by an advection-diffusion equation:

$\frac{\partial c}{\partial t}=\frac{\partial}{\partial x}\left(D_{\text {eff }} \frac{\partial c}{\partial x}-u c\right)$

where $u[\mathrm{~m} / \mathrm{s}]$ is the macroscopic velocity of the liquid in the porous material (namely, the Darcy velocity).

Two extreme cases can be identified: absorption and drying. In absorption (or water uptake), the liquid velocity is dominated by capillary forces and therefore depends on surface tension, contact angle and pore size. In drying, the liquid velocity is dominated by the boundary condition, in particular by the balance between evaporation and advection rates.

\subsection{Péclet number}

Eq. (5) indicates that advection can accumulate ions near the drying surface, whereas diffusion tries to level off their concentration throughout a system. On the right-hand side of that equation, the first term describes the diffusive flux, whereas the second term describes the advection of the ions along with the liquid flow. The competition between the transport mechanisms can be characterized on a macroscopic level where the Darcy equation is valid with a dimensionless parameter known as the Péclet number. Based on Eq. (5), it can be defined as:

$P e=\frac{u L}{D_{\text {eff }}}$

where $L$ is a so-called characteristic length scale, which most often can be chosen as the length of the sample. In the case $P e \gg>1$, advection dominates and a concentration gradient is established. An accumulation of ions at or close to the surface gives rise to crystallization as soon as the saturation concentration is reached (assuming nucleation is easy). In contrast, if $P e \ll 1$, diffusion is dominant and we expect a homogenous distribution of salt. This means that salts can be redistributed towards zones of lower concentration, so that accumulation and high supersaturations are avoided, in particular in the subsurface, meaning the damage from crystallization pressure should be reduced.

A delicate part in determining $P e$ consists in obtaining reliable values for the fluid velocity, $u$. In drying experiments $P e$ numbers are found between 1 and 40 . Measurements of drying rates on site could be considered and portable devices to access such properties are being developed [76]. With such data, Pe could be estimated, helping to select laboratory conditions best representing field exposure. Another complication in cases of salt accumulation is that the blocking of pores modifies the fluid velocity. In principle, this is something that a laboratory test should also be able to capture [77]. One may, however, apply different conditions during an accumulation phase, to prepare samples before subjecting them to conditions more similar to field exposure and the target $P e$ value.

\subsection{Crystallization and growth kinetics}

When supersaturation develops, a sink term needs to be included in Eq. (6) describing the precipitation reaction, typically represented by a kinetic law [78]. One assumption is that the rate of formation is proportional to concentration in excess of the saturation concentration $c^{*}$ :

$\frac{\partial c}{\partial t}=\frac{\partial}{\partial x}\left(D_{e f f} \frac{\partial c}{\partial x}-u c\right)-k\left(c-c^{*}\right)$

were $k$ is a crystallization kinetics parameter (growth rate constant), in which the effects of nucleation, bulk crystal growth, and pore structure (connectivity, pore size and specific surface) are lumped together. From such an equation and using an appropriate numerical approach, it is possible to calculate the rate of salt accumulation, as well as its distribution in a sample. The next section presents a concise outline for this.

\section{Numerical approaches}

To capture the complex interactions between varying environmental conditions and the processes inside the pore space, including precipitation, pressure buildup, heat and mass transfer, numerical tools have been developed to simulate crystallization problems on multiple scales. This calls for solving a coupled set of equations describing heat and mass transport in the porous material, salt crystallization, and the mechanical response to temperature, moisture and salt content changes, as well as thermal, hygric and crystallization-induced fracturing. The environmental conditions define the boundary conditions. Given the nonlinear nature of the equations and their coupling, numerical approaches are needed. Typical ones used in the literature are control volume, finite element, and finite difference. Numerical codes were developed throughout the years [79], initially focusing on the coupled transportcrystallization equations [80-83] and subsequently on the coupling with the mechanical response by introducing poromechanics $[43,84,85]$ and fracture mechanics [86].

The accuracy of these simulations strongly depends on the input parameters, and therefore a good knowledge of the material, fluid, and salt properties is crucial. Complete characterization of a porous material should include measurements of thermal capacity and conductivity, moisture retention curve and permeability, and mechanical properties, as thermal expansion coefficient, Young's modulus, Poisson's ratio, tensile strength, and Biot coefficient. For unsaturated conditions, the moisture retention curve is defined by the volume of pores that is filled by moisture at a given capillary pressure. Similarly, the liquid permeability varies as a function of capillary pressure, and depends on the connectivity between liquid-filled pores at a given capillary pressure. Often, the capillary absorption coefficient is determined in the laboratory as a measure for liquid permeability. However, this only reflects the permeability at the capillary saturated state, whereas the unsaturated permeability [87] is crucial for a correct modelling of the moisture profiles during wetting or drying 
events. The evolution of moisture profiles then defines the location of salt precipitation, inside the material or on its surface, and for subflorescence, the size of the zone in which salt crystals accumulate.

In addition to intrinsic material properties, fluid properties need to be known, including fluid density, surface tension and viscosity, as well as the influence of temperature and salt concentration on these properties. Salt properties comprise the latent heat of crystallization, the ion and water activities [88], and crystallization kinetics.

Although a very rich dataset on material, fluid, and salt properties can be collected, certain physical aspects remain uncertain in the numerical models. Once crystals precipitate as subflorescence, they influence the moisture retention curve and permeability, as less pore space is available, and pores can get clogged [89]. The changes in transport properties depend on which fraction of the porosity gets filled by crystals (pore sizes and volume fraction). In addition, pore filling also influences the calculation of crystallization pressure. Different filling paths can be assumed: from large to small pores, from small to large, or a uniform distribution of crystals over all pore sizes.

Numerical models at the pore scale were developed to assess the influence of the filling path on crystallizationinduced stresses $[90,91]$. However, the pore filling itself remains difficult to model, and depends on the pore structure, as well as on the process triggering crystallization (e.g. drying, cooling, or rewetting). Efflorescence influences transport, as it forms a new porous layer on the existing porous structure. In a macroscale numerical description, efflorescence can be incorporated as a changing boundary condition, but its definition remains tailored to the specific type of efflorescence and no generally valid expression exists [92].

Despite these uncertainties, it should be possible to make satisfactory assumptions about material properties and exposure conditions. A numerical model can be used to assess how variation of these properties affects the overall material behaviour. In this way, the sensitivity to each property can be assessed, shedding light both on the properties that matter most and on those for which only limited accuracy is needed.

When thinking of a laboratory salt weathering test, we typically think of a freestanding porous building material (or combination of materials) that is subjected to temperature and/or humidity cycles. Under these conditions, the effective stress can be approximated by accounting only for the crystallization-induced stress $[25,26,83,84,90]$. The mathematical problem thus simplifies and can be decoupled; that is, the stress can be calculated for each time step after solving the coupled heat and mass transport problem. The main asset of numerical simulations over analytical solutions is that they can account for complex boundary conditions (e.g. real climate data). Numerical simulations could therefore be used to test whether a simplified climate protocol for a laboratory test induces the same weathering response as the field exposure considered.

\section{Conclusions and outlook}

The goal of this review is to contribute to better defining the questions and identifying possible approaches to designing the most meaningful possible tests for salt damage. For this, we adapt one of the most quoted works on the durability of reinforced concrete [93]. It introduces the notions of "induction time" and "propagation phase". For reinforced concrete, referring respectively to the time before steel rebars starts to corrode (involving transport of either chlorides or carbon dioxide), and the period during which corrosion develops after critical conditions are reached at their surface (referred to as "damage onset" in Fig. 6).

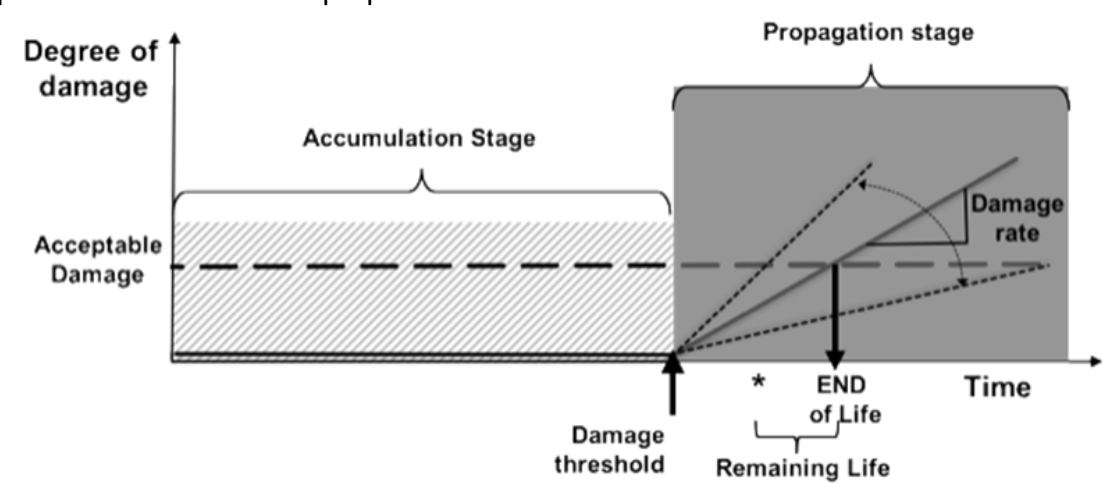

Figure 6. Schematic representation of durability of a stone subject to salt damage, adapted from the concept proposed by Tuutti to describe the durability of reinforced concrete [93]. The graph shows a first "accumulation phase", during which salts deposit in the porous material, but are not yet present in large enough amounts to damage it. Damage starts to develop after the "damage onset" and progresses at the "damage rate". Stones may however remain in place until a level of "acceptable damage" is exceeded. If confronted in knowing how much more time a degrading stone may be left in place beyond at certain time (marked by "*” in the graph), then the value of the "damage rate" is the most important factor in determining the "remaining service life". If the question concerns the selection of the most adequate replacement material, then the "service life" will most probably be conditioned by the "accumulation stage" and laboratory testing should focus on this rather than on damage propagation. 
This concept can be transferred to salt damage (Fig. 6). Indeed, from the poromechanical treatment (section 2.4), we underlined that the fraction of filled pores plays an important role in the macroscopic stress. As crystallization pressure cannot be arbitrarily high in field exposure, it is necessary to accumulate a certain amount of salt before damage initiates. Conditions and rates under which this occurs could be estimated qualitatively from a Péclet number (section 4.2) and semi-quantitatively from numerical modelling (section 5). The duration of this "accumulation phase" is probably the one of greatest concern when having to select new or replacement materials. Hence, when facing such questions, tests oriented at rates of salt accumulation would be the most relevant ones. From a numerical point of view, such situations are easier to model, implying that there is a significant potential of using modeling to assess the relevance (or not) of a given test for given exposure conditions. Of course, this requires accurate data regarding the environmental conditions on site over time (e.g. $\mathrm{RH}, T$, rainfall, ground saturation, and pollution levels).

The propagation phase is quite difficult to predict, because the material becomes increasingly damaged and it is unclear which mechanical properties to use and which failure propagation criteria to use at what scale. Such situations would have to be studied if the question posed is "how much longer can a material undergoing degradation still be left in place". This introduces the notion of "acceptable damage", which depends on the situation considered, has a subjective component, and is clearly different between a stone serving a decorative or a structural function. When faced with such questions it is conceivable that tests should be designed in which a benign accumulation phase is first used to accumulate the salts in a small and meaningful volume of the specimen. This would be followed by another test producing crystallization pressure, possibly in cycles, to test the resistance of building materials in a way that will be more representative of field exposure. It would provide the damage rate in Fig. 6.

In summary, we suggest that the poromechanical insight provides an important argumentation for separating salt damage into two phases: induction and propagation. When considering replacement stones, bricks or mortars, tests should focus on the rate of salt accumulation. Modelling, as well as estimates of Péclet numbers, can provide guidelines to define exposure classes and corresponding relevant tests. When dealing with the question of "remaining service life", tests could be separated in two phases. A first phase would only serve to accumulate salts without inducing damage. A second would serve to initiate and propagate damage to determine a damage rate more representative of practice.

\section{Acknowledgements}

Authors are grateful to all members of the RILEM TC 271ASC for fruitful discussions on the subject of this paper. Nevin Aly was supported by the Swiss government excellence postdoctoral scholarship (2016.0766 / Aegypten / OP). Carlos Rodriguez Navarro acknowledges support by the
Spanish Government (grant CGL2015-70642-R), the Junta de Andalucía (Research Group RNM-179), and the University of Granada ("Unidad Científica de Excelencia" UCE-PP2016-05). The authors also thank an anonymous reviewer for a thourough reading and many suggestions that will be taken up for further consideration in the work of the RILEM TC 271-ASC.

\section{References}

[1] ICOMOS International Scientific Committee for Stone (ISCS), Monuments\&Sites XV - Illustrated glossary on stone deterioration patterns, Ateliers 30 Impression, Champigny/Marne, France, 2008.

[2] A. Arnold, K. Zehnder, Salt weathering on monuments, in: Proc 1st Int Symp. Conserv. Monum. Mediterr. Basin Bari Zezza F Ed, Bari, 1989, 31-58.

[3] R. Snethlage, K. Sterflinger, Stone Conservation, in: Stone Archit., Springer, Berlin, Heidelberg, 2011, 411-544. https://doi.org/10.1007/978-3-642-14475-2 7

[4] EN 12370:1999, Natural stone test methods: Resistance to salt crystallization, 1999.

[5] C. Rodriguez-Navarro, E. Doehne, Salt weathering: influence of evaporation rate, supersaturation and crystallization pattern, Earth Surf. Process. Landf. (1999) 24: 191-209. https://doi.org/10.1002/(SICI)1096-9837(199903)24:3<191::AIDESP942>3.0.CO;2-G

[6] A.S. Goudie, H.A. Viles, Salt Weathering Hazards. Wiley: 1997.

[7] S.Z. Lewin, The mechanism of masonry decay through crystallization, in: S.M. Barkin (Ed.), Conserv. Hist. Stone Build. Monum., National Acad. Press, Washington DC, USA, 1982: pp. 120-144.

[8] C. Rodriguez-Navarro, E. Doehne, Time-lapse video and ESEM: Integrated tools for understanding processes in situ. American laboratory (1999) 31(10):28-35.

[9] B. Lubelli, et al., Towards a Towards a more effective and reliable salt crystallization test for porous building materials: inputs from past experience, Mater. Struct. 2018 (to be submitted) (n.d.).

[10] D. Benavente, M.A. García del Cura, A. Bernabéu, S. Ordóñez, Quantification of salt weathering in porous stones using an experimental continuous partial immersion method, Eng. Geol. 59 (2001) 313-325. https://doi.org/10.1016/S0013-7952(01)00020-5

[11] A. Aubret, S. Ramananarivo, J. Palacci, Eppur si muove, and yet it moves: Patchy (phoretic) swimmers, Curr. Opin. Colloid Interface Sci. 30 (2017) 81-89. https://doi.org/10.1016/i.cocis.2017.05.007

[12] G.W. Scherer, Crystallization in pores, Cem. Concr. Res. 29 (1999) 1347-1358. https://doi.org/10.1016/S0008-8846(99)00002-2

[13] G.W. Scherer, Stress from crystallization of salt, Cem. Concr. Res. 34 (2004) 1613-1624 https://doi.org/10.1016/j.cemconres.2003.12.034

[14] G.W. Scherer, Stress from crystallization of salt in pores, in: Proc 9th Int Cong Deterioration Conserv. Stone V Fassina Ed, Elsevier, Amsterdam, 2000: pp. 187-194. https://doi.org/10.1016/B978-044450517-0/50100-8

[15] M. Steiger, Crystal growth in porous materials-I: The crystallization pressure of large crystals, J. Cryst. Growth. 282 (2005) 455-469. https://doi.org/10.1016/j.jcrysgro.2005.05.007

[16] G.W. Scherer, R. Flatt, G. Wheeler, Materials Science Research for the Conservation of Sculpture and Monuments, MRS Bull. 26 (2001) 44-50. https://doi.org/10.1557/mrs2001.18

[17] C.W. Correns, W. Steinborn, Experimente zur Messung und Erklärung der sogenannten Kristallisationskraft, Z. Für Krist. - Cryst. Mater. 101 (2015) 117-133. https://doi.org/10.1524/zkri.1939.101.1.117

[18] C.W. Correns, Growth and dissolution of crystals under linear pressure, Discuss. Faraday Soc. 5 (1949) 267-271. https://doi.org/10.1039/df9490500267

[19] R.J. Flatt, M. Steiger, G.W. Scherer, A commented translation of the paper by C.W. Correns and W. Steinborn on crystallization pressure, Environ. Geol. 52 (2007) 187. https://doi.org/10.1007/s00254-006-0509-5

[20] M. Buil, Thermodynamic and experimental study of the crystallization pressure of water-soluble salts, in: Mater. Sci. Restor. Lack Chem., Wittmann FH (ed), Filderstadt, n.d.: pp. 373-377. 
[21] A. Røyne, D.K. Dysthe, Rim formation on crystal faces growing in confinement, J. Cryst. Growth. 346 (2012) 89-100. https://doi.org/10.1016/j.jcrysgro.2012.03.019

[22] J. Désarnaud, O. Grauby, P. Bromblet, J.-M. Vallet, A. Baronnet, Growth and Dissolution of Crystal under Load: New Experimental Results on KCl, Cryst. Growth Des. 13 (2013) 1067-1074. https://doi.org/10.1021/cg3013359

[23] J. Desarnaud, D. Bonn, N. Shahidzadeh, The Pressure induced by salt crystallization in confinement, Sci. Rep. 6 (2016) 30856. https://doi.org/10.1038/srep30856

[24] L.A. Rijniers, H.P. Huinink, L. Pel, K. Kopinga, Experimental Evidence of Crystallization Pressure inside Porous Media, Phys. Rev. Lett. 94 (2005) 075503. https://doi.org/10.1103/PhysRevLett.94.075503

[25] R.M. Espinosa-Marzal, A. Hamilton, M. McNall, K. Whitaker, G.W. Scherer, The chemomechanics of crystallization during rewetting of limestone impregnated with sodium sulfate, J. Mater. Res. 26 (2011) 1472-1481. https://doi.org/10.1557/imr.2011.137

[26] R.J. Flatt, F. Caruso, A.M.A. Sanchez, G.W. Scherer, Chemomechanics of salt damage in stone, Nat. Commun. 5 (2014) 4823. https://doi.org/10.1038/ncomms5823

[27] M. Steiger, Crystal growth in porous materials-II: Influence of crystal size on the crystallization pressure, J. Cryst. Growth. 282 (2005) 470-481. https://doi.org/10.1016/i.jcrysgro.2005.05.008

[28] H. Freundlich, Colloid and Capillary Chemistry Translated from the 3rd German Edition by H. Stafford Hatfield, 1926.

[29] M. Schiro, E. Ruiz-Agudo, C. Rodriguez-Navarro, Damage Mechanisms of Porous Materials due to In-Pore Salt Crystallization, Phys. Rev. Lett. 109 (2012) 265503. https://doi.org/10.1103/PhysRevLett.109.265503

[30] R.J. Flatt, Salt damage in porous materials: how high supersaturations are generated, J. Cryst. Growth. 242 (2002) 435454. https://doi.org/10.1016/S0022-0248(02)01429-X

[31] J. Desarnaud, F. Bertrand, N. Shahidzadeh-Bonn, Impact of the Kinetics of Salt Crystallization on Stone Damage During Rewetting/Drying and Humidity Cycling, J. Appl. Mech. 80 (2013) 020911-020911-7. https://doi.org/10.1115/1.4007924

[32] N. Tsui, R.J. Flatt, G.W. Scherer, Crystallization damage by sodium sulfate, J. Cult. Herit. 4 (2003) 109-115. https://doi.org/10.1016/S1296-2074(03)00022-0

[33] H.F.W. Taylor, C. Famy, K.L. Scrivener, Delayed ettringite formation, Cem. Concr. Res. 31 (2001) 683-693. https://doi.org/10.1016/S0008-8846(01)00466-5

[34] R.J. Flatt, G.W. Scherer, Thermodynamics of crystallization stresses in DEF, Cem. Concr. Res. 38 (2008) 325-336. https://doi.org/10.1016/j.cemconres.2007.10.002

[35] M. Steiger, S. Asmussen, Crystallization of sodium sulfate phases in porous materials: The phase diagram Na2SO4- $\mathrm{H} 2 \mathrm{O}$ and the generation of stress, Geochim. Cosmochim. Acta. 72 (2008) 42914306. https://doi.org/10.1016/j.gca.2008.05.053

[36] N. Lindström, T. Talreja, K. Linnow, A. Stahlbuhk, M. Steiger, Crystallization behavior of $\mathrm{Na} 2 \mathrm{SO} 4-\mathrm{MgSO} 4$ salt mixtures in sandstone and comparison to single salt behavior, Appl. Geochem. 69 (2016) 50-70. https://doi.org/10.1016/i.apgeochem.2016.04.005

[37] E. Balboni, R.M. Espinosa-Marzal, E. Doehne, G.W. Scherer, Can drying and re-wetting of magnesium sulfate salts lead to damage of stone?, Environ. Earth Sci. 63 (2011) 1463-1473. https://doi.org/10.1007/s12665-010-0774-1

[38] M. Steiger, K. Linnow, H. Juling, G. Gülker, A.E. Jarad, S. Brüggerhoff, D. Kirchner, Hydration of MgSO4. $\mathrm{H} 2 \mathrm{O}$ and Generation of Stress in Porous Materials, Cryst. Growth Des. 8 (2008) 336-343. https://doi.org/10.1021/cg060688c

[39] P. Lopez-Arce, J. Garcia-Guinea, D. Benavente, L. Tormo, E. Doehne, Deterioration of dolostone by magnesium sulphate salt: An example of incompatible building materials at Bonaval Monastery, Spain, Constr. Build. Mater. 23 (2009) 846-855. https://doi.org/10.1016/j.conbuildmat.2008.04.001

[40] E. Ruiz-Agudo, F. Mees, P. Jacobs, C. Rodriguez-Navarro, The role of saline solution properties on porous limestone salt weathering by magnesium and sodium sulfates, Environ. Geol. 52 (2007) 269-281. https://doi.org/10.1007/s00254-006-0476-x

[41] S. Dean, H. Haynes, ASTM C 88 Test on Soundness of Aggregate Using Sodium Sulfate or Magnesium Sulfate: A Study of the Mechanisms of Damage, J. ASTM Int. 2 (2005) 12517. https://doi.org/10.1520/JAl12517

[42] J. Thompson, On the disintegration of stones exposed in buildings and otherwise to atmospheric influence, Rep. Annu. Meet. Br. Assoc. Adv. Sci. (1862) 35.
[43] O. Coussy, Deformation and stress from in-pore drying-induced crystallization of salt, J. Mech. Phys. Solids. 54 (2006) 1517-1547. https://doi.org/10.1016/j.jmps.2006.03.002

[44] D. Fabre, J. Gustkiewicz, Influence of rock porosity on the Biot's coefficient, A a Balkema Publishers, Leiden, 1998.

[45] C. Hall, W.D. Hoff, Rising damp: capillary rise dynamics in walls, Proc. R. Soc. Lond. Math. Phys. Eng. Sci. 463 (2007) 1871-1884. https://doi.org/10.1098/rspa.2007.1855

[46] S. Veran-Tissoires, M. Marcoux, M. Prat, Discrete Salt Crystallization at the Surface of a Porous Medium, Phys. Rev. Lett. 108 (2012) 054502. https://doi.org/10.1103/PhysRevLett.108.054502

[47] L. Guglielmini, A. Gontcharov, A.J. Aldykiewicz, H.A. Stone, Drying of salt solutions in porous materials: Intermediate-time dynamics and efflorescence, Phys. Fluids. 20 (2008) 077101. https://doi.org/10.1063/1.2954037

[48] Commission 25-PEM Protection et érosion des monuments, Matér. Constr. 13 (1980) 175-253. https://doi.org/10.1007/BF02473564

[49] V. López-Acevedo, C. Viedma, V. Gonzalez, A. La Iglesia, Salt crystallization in porous construction materials. II. Mass transport and crystallization processes, J. Cryst. Growth. 182 (1997) 103-110. https://doi.org/10.1016/S0022-0248(97)00341-2

[50] C. Rodriguez-Navarro, E. Doehne, E. Sebastian, Influencing Crystallization Damage in Porous Materials through the Use of Surfactants: Experimental Results Using Sodium Dodecyl Sulfate and Cetyldimethylbenzylammonium Chloride, Langmuir. 16 (2000) 947-954. https://doi.org/10.1021/la990580h

[51] C. Rodriguez-Navarro, L.G. Benning, Control of Crystal Nucleation and Growth by Additives, Elements. 9 (2013) 203-209. https://doi.org/10.2113/gselements.9.3.203

[52] E. Ruiz-Agudo, C. Rodriguez-Navarro, E. Sebastián-Pardo, Sodium Sulfate Crystallization in the Presence of Phosphonates: Implications in Ornamental Stone Conservation, Cryst. Growth Des. 6 (2006) 1575-1583. https://doi.org/10.1021/cg050503m

[53] E. Ruiz-Agudo, C.V. Putnis, L. Pel, C. Rodriguez-Navarro, TemplateAssisted Crystallization of Sulfates onto Calcite: Implications for the Prevention of Salt Damage, Cryst. Growth Des. 13 (2013) 40-51. https://doi.org/10.1021/cg300744x

[54] B. Lubelli, R.P.J. van Hees, Effectiveness of crystallization inhibitors in preventing salt damage in building materials, J. Cult. Herit. 8 (2007) 223-234. https://doi.org/10.1016/i.culher.2007.06.001

[55] B. Lubelli, T.G. Nijland, R.P.J. van Hees, A. Hacquebord, Effect of mixed in crystallization inhibitor on resistance of lime-cement mortar against $\mathrm{NaCl}$ crystallization, Constr. Build. Mater. 24 (2010) 2466-2472. https://doi.org/10.1016/i.conbuildmat.2010.06.010

[56] C. Selwitz, E. Doehne, The evaluation of crystallization modifiers for controlling salt damage to limestone, J. Cult. Herit. 3 (2002) 205216. https://doi.org/10.1016/S1296-2074(02)01182-2

[57] C. Rodriguez-Navarro, L. Linares-Fernandez, E. Doehne, E. Sebastian, Effects of ferrocyanide ions on $\mathrm{NaCl}$ crystallization in porous stone, J. Cryst. Growth. 243 (2002) 503-516. https://doi.org/10.1016/S0022-0248(02)01499-9

[58] A. Hamed, N. Aly, M. Gomez-Heras, M.A. de Buergo, New experimental method to study the combined effect of temperature and salt weathering, Geol. Soc. Lond. Spec. Publ. 416 (2016) 229237. https://doi.org/10.1144/SP416.18

[59] B. Lubelli, R.P.J. van Hees, H.P. Huinink, C.J.W.P. Groot, Irreversible dilation of $\mathrm{NaCl}$ contaminated lime-cement mortar due to crystallization cycles, Cem. Concr. Res. 36 (2006) 678-687. https://doi.org/10.1016/i.cemconres.2005.10.008

[60] N. Shahidzadeh-Bonn, J. Desarnaud, F. Bertrand, X. Chateau, D. Bonn, Damage in porous media due to salt crystallization, Phys. Rev. E. 81 (2010) 066110. https://doi.org/10.1103/PhysRevE.81.066110

[61] M.F.C. Denecker, R.L. Hebert, J. Wassermann, G. Dosseh, B. Menendez, A. Bourgès, Experimental study of the crystallization of sodium sulfate hydrates through temperature monitoring, Environ. Earth Sci. 72 (2014) 5089-5099. https://doi.org/10.1007/s12665-014-3379-2

[62] J. Desarnaud, H. Derluyn, L. Molari, S. de Miranda, V. Cnudde, N. Shahidzadeh, Drying of salt contaminated porous media: Effect of primary and secondary nucleation, J. Appl. Phys. 118 (2015) 114901. https://doi.org/10.1063/1.4930292

[63] T.A. Saidov, L. Pel, K. Kopinga, Sodium sulfate salt weathering of porous building materials studied by NMR, Mater. Struct. 50 (2017) 145. https://doi.org/10.1617/s11527-017-1007-9

[64] M. Steiger, Salts in Porous Materials: Thermodynamics of Phase Transitions, Modeling and Preventive Conservation / Salze in porösen Materialien: Thermodynamische Analyse von 
Phasenübergängen, Modellierung und passive Konservierung, Restor. Build. Monum. 11 (2014) 419-432. https://doi.org/10.1515/rbm-2005-6002

[65] M. Steiger, E.A. charola, K. sterflinger, Weathering and deterioration, in: Stone Archit. - Prop. Durab. Siegfried Siegesmund Springer, Springer-Verlag Berlin, 2014: pp. 225-316. https://doi.org/10.1007/978-3-642-45155-3 4

[66] C. Cardell, D. Benavente, J. Rodríguez-Gordillo, Weathering of limestone building material by mixed sulfate solutions. Characterization of stone microstructure, reaction products and decay forms, Mater. Charact. 59 (2008) 1371-1385. https://doi.org/10.1016/j.matchar.2007.12.003

[67] P. Lopez-Arce, E. Doehne, W. Martin, S. Pinchin, Magnesium sulfate salts and historic building materials: experimental simulation of limestone flaking by relative humidity cycling and crystallization of salts, Mater. Constr. 58 (2008) 125-142. https://doi.org/10.3989/mc.2008.v58.i289-290.77

[68] C. Franzen, P.W. Mirwald, Moisture sorption behaviour of salt mixtures in porous stone, Chem. Erde - Geochem. 69 (2009) 91-98. https://doi.org/10.1016/j.chemer.2008.02.001

[69] H.D. Clercq, M. Jovanović, K. Linnow, M. Steiger, Performance of limestones laden with mixed salt solutions of $\mathrm{Na} 2 \mathrm{SO} 4-\mathrm{NaNO} 3$ and Na2SO4-K2SO4, Environ. Earth Sci. 69 (2013) 1751-1761. https://doi.org/10.1007/s12665-012-2017-0

[70] K. Linnow, M. Steiger, C. Lemster, H.D. Clercq, M. Jovanović, In situ Raman observation of the crystallization in NaNO3-Na2SO4- $\mathrm{H} 2 \mathrm{O}$ solution droplets, Environ. Earth Sci. 69 (2013) 1609-1620. https://doi.org/10.1007/s12665-012-1997-0

[71] N. Lindström, N. Heitmann, K. Linnow, M. Steiger, Crystallization behavior of $\mathrm{NaNO}-\mathrm{Na2SO} 4$ salt mixtures in sandstone and comparison to single salt behavior, Appl. Geochem. 63 (2015) 116132. https://doi.org/10.1016/j.apgeochem.2015.07.007

[72] H.P. Huinink, L. Pel, M. a. J. Michels, How ions distribute in a drying porous medium: A simple model, Phys. Fluids. 14 (2002) 13891395. https://doi.org/10.1063/1.1451081

[73] L. Pel, H. Huinink, K. Kopinga, Ion transport and crystallization in inorganic building materials as studied by nuclear magnetic resonance, Appl. Phys. Lett. 81 (2002) 2893-2895. https://doi.org/10.1063/1.1512329

[74] J. Petković, H.P. Huinink, L. Pel, K. Kopinga, R.P.J. van Hees, Salt transport in plaster/substrate layers, Mater. Struct. 40 (2007) 475. https://doi.org/10.1617/s11527-006-9151-7

[75] L. Pel, A. Sawdy, V. Voronina, Physical principles and efficiency of salt extraction by poulticing, J. Cult. Herit. 11 (2010) 59-67. https://doi.org/10.1016/j.culher.2009.03.007

[76] A. Stahlbuhk, M. Niermann, M. Steiger, Determination of the water uptake and drying behavior of masonry using a non-destructive method., in: Proc. SWBSS 2017 Fourth Int. Conf. Salt Weather. Build. Stone Sculpt., Ed. Laue. S, Postdam, Germany, 2017: pp. 5764.

[77] R.M. Espinosa-Marzal, G.W. Scherer, Impact of in-pore salt crystallization on transport properties, Environ. Earth Sci. 69 (2013) 2657-2669. https://doi.org/10.1007/s12665-012-2087-z

[78] J.W. Mullin, 6 - Crystal growth, in: Cryst. Fourth Ed., ButterworthHeinemann, Oxford, 2001: pp. 216-288. https://doi.org/10.1016/B978-075064833-2/50008-5

[79] R. Snethlage, E. Wendler, Moisture Cycles and Sandstone Degradation, in: Sav. Our Archit. Herit. Conserv. Hist. Stone Struct. Rep. Dahl. Workshop Sav. Our Archit. Heritag, Wiley, New York, 1997: pp. 7-24.

[80] R.M. Espinosa, L. Franke, G. Deckelmann, C. Gunstmann, Gekoppelter Wärme- und Stofftransport einschließlich der Korrosionsprozesse in porösen Baustoffen mit dem Simulationsprogramm AStra, Bauphysik. 29 (2007) 187-193. https://doi.org/10.1002/bapi.200710026

[81] A. Nicolai, J. Grunewald, J.S. Zhang, Salztransport und Phasenumwandlung - Modellierung und numerische Lösung im Simulationsprogramm Delphin 5, Bauphysik. 29 (2007) 231-239. https://doi.org/10.1002/bapi.200710032

[82] M. Koniorczyk, Salt transport and crystallization in non-isothermal, partially saturated porous materials considering ions interaction model, Int. J. Heat Mass Transf. 55 (2012) 665-679. https://doi.org/10.1016/i.ijheatmasstransfer.2011.10.043

[83] G. Castellazzi, C. Colla, S. de Miranda, G. Formica, E. Gabrielli, L. Molari, F. Ubertini, A coupled multiphase model for hygrothermal analysis of masonry structures and prediction of stress induced by salt crystallization, Constr. Build. Mater. 41 (2013) 717-731. https://doi.org/10.1016/j.conbuildmat.2012.12.045
[84] H. Derluyn, P. Moonen, J. Carmeliet, Deformation and damage due to drying-induced salt crystallization in porous limestone, J. Mech. Phys. Solids. 63 (2014) 242-255. https://doi.org/10.1016/j.jmps.2013.09.005

[85] M. Koniorczyk, D. Gawin, Modelling of salt crystallization in building materials with microstructure - Poromechanical approach, Constr. Build. Mater. 36 (2012) 860-873. https://doi.org/10.1016/j.conbuildmat.2012.06.035

[86] H. Derluyn, Salt transport and crystallization in porous limestone: neutron - X-ray imaging and poromechanical modeling, Diss. ETH No. 20673, ETH Zurich, Switzerland, 2012.

[87] J. Carmeliet, H. Hens, S. Roels, O. Adan, H. Brocken, R. Cerny, Z. Pavlik, C. Hall, K. Kumaran, L. Pel, Determination of the Liquid Water Diffusivity from Transient Moisture Transfer Experiments, J. Build. Phys. 27 (2004) 277-305. https://doi.org/10.1177/1097196304042324

[88] M. Steiger, J. Kiekbusch, A. Nicolai, An improved mode incorporating Pitzer's equations for calculation of thermodynamic properties of pore solutions implemented into an efficient program code, Constr. Build. Mater. 22 (2008) 1841-1850. https://doi.org/10.1016/i.conbuildmat.2007.04.020

[89] R.M. Espinosa-Marzal, G.W. Scherer, Impact of in-pore salt crystallization on transport properties, Environ. Earth Sci. 69 (2013) 2657-2669. https://doi.org/10.1007/s12665-012-2087-z

[90] R.M. Espinosa, L. Franke, G. Deckelmann, Model for the mechanical stress due to the salt crystallization in porous materials, Constr. Build. Mater. 22 (2008) 1350-1367. https://doi.org/10.1016/j.conbuildmat.2007.04.013

[91] L. Grementieri, F. Daghia, L. Molari, G. Castellazzi, H. Derluyn, V. Cnudde, S. de Miranda, A multi-scale approach for the analysis of the mechanical effects of salt crystallisation in porous media, Int. J. Solids Struct. 126 (2017) 225-239. https://doi.org/10.1016/j.ijsolstr.2017.08.009

[92] L. Grementieri, L. Molari, H. Derluyn, J. Desarnaud, V. Cnudde, N. Shahidzadeh, S. De Miranda, Numerical simulation of salt transport and crystallization in drying Prague sandstone using an experimentally consistent multiphase model, Build. Environ. 123 (2017) 289-298. doi:10.1016/.

[93] K. Tuutti, Corrosion of steel in concrete, CBI Forsk. 824. (1982). http://lup.lub.lu.se/record/3173286 (accessed September 20, 2017).

[94] J. Desarnaud, H. Derluyn, L. Grementieri, L. Molari, S. de Miranda, V. Cnudde, N. Shahidzadeh, Salt contaminated sandstone under environmental loading:recrystallization process and its consequences, in: Proc. Int. RILEM Conf. Mater. Syst. Struct. Civ. Eng. 2016 Segm. Hist. Mason. Ed Inge Rörig-Dalgaard loannis loannou, RILEM Publications S.A.R.L., Lyngby, Denmark, 2016: pp. 127-136.

[95] R.J. Flatt, G.W. Scherer, J.W. Bullard, Why alite stops hydrating below $80 \%$ relative humidity, Cem. Concr. Res. 41 (2011) 987-992. https://doi.org/10.1016/j.cemconres.2011.06.001 